For the Table of Contents entry

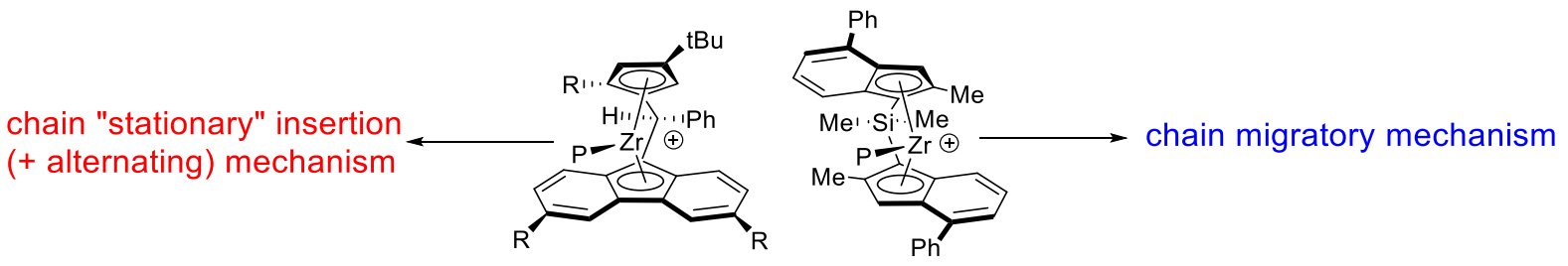

Origins of stereoselectivity in propylene polymerization for a series of isoselective metallocenes belonging to two different families, namely $C_{1}$-symmetric $\{\mathrm{Cp} / \mathrm{Flu}\}$-type and $C_{2}$-symmetric $\{\mathrm{SBI}\}$-type systems, were apprehended by theoretical calculations using an improved DFT model, and meso/rac pentad distributions were predicted with good precision. 


\title{
A Theoretical Outlook on the Stereoselectivity Origins of Isoselective Zirconocene Propylene Polymerization Catalysts
}

Ludovic Castro, ${ }^{1,2}$ Gabriel Therukauff, ${ }^{2}$ Aurelien Vantomme ${ }^{3}$, Alexandre Welle ${ }^{3}$, Luc Haspeslagh, ${ }^{4}$ Jean-Michel Brusson, ${ }^{4}$ Laurent Maron, ${ }^{1, *}$ Jean-François Carpentier, ${ }^{2, *}$ and Evgueni Kirillov²,*

1 Université de Toulouse, INSA, UPS and CNRS, LPCNO, UMR 5215, 135 avenue de Rangueil, F-31077 Toulouse, France

${ }^{2}$ Univ Rennes, CNRS, ISCR - UMR 6226, F-35000 Rennes, France

${ }^{3}$ Total Research \& Technology Feluy, Zone Industrielle C, B-7181 Feluy, Belgium

${ }^{4}$ Total S.A., Direction Scientifique, 24 Cours Michelet, F-92069 Paris La Défense Cedex, France

\begin{abstract}
The first three insertion steps of propylene for isoselective metallocenes from the $\{\mathrm{Cp} / \mathrm{Flu}\}-$ and $\{\mathrm{SBI}\}$-families were computed using a theoretical method implementing the B3PW91 functional in combination with solvent corrections incorporated with the SMD continuum model. For the $C_{1}$-symmetric $\{\mathrm{Cp} / \mathrm{Flu}\}$-type metallocenes, two mechanisms of stereocontrol were validated theoretically: more facile and more stereoselective chain "stationary" insertion (or site epimerization back-skip) and less stereoselective alternating mechanisms. For the $C_{2}$-symmetric $\{\mathrm{SBI}\}$-type system, computation results are in complete agreement with the sole operating chain migratory insertion mechanism. The thermochemical data obtained through the study were used to predict microstructures of polypropylenes using three-parameter and one-parameter statistical models for the two metallocene systems, respectively. The calculated meso/rac pentad distributions were found in good agreement
\end{abstract}


with those determined experimentally for iPP samples obtained at different polymerization temperatures.

\section{INTRODUCTION}

Highly isotactic polypropylene (iPP) can be efficiently produced using two main families of zirconocene precatalysts: (i) $C_{1}$-symmetric one-carbon-bridged cyclopentadienylfluorenyl ( $\left\{\mathrm{R}^{1} \mathrm{R}^{2} \mathrm{C}-(\mathrm{Flu})(\mathrm{Cp})\right\}$, hereafter referred to as $\{\mathrm{Cp} / \mathrm{Flu}\}, \mathbf{1 - R}$ and $\mathbf{2}$, Scheme 1) and (ii) $C_{2}$-symmetric silicon-bridged ansa-bis(indenyl) $\left(\left\{\mathrm{R}_{2}^{1}{ }_{2} \mathrm{Si}-\left(2-\mathrm{Me}-4-\mathrm{R}^{2}-\mathrm{Ind}\right)_{2}\right\}\right.$ or $\left.\{\mathrm{SBI}\}, 3\right) .{ }^{1}$ Understanding the actual mechanism of stereocontrol operating with those systems, which allows engineering of more stereoselective catalysts, has been the subject of numerous studies. $^{2}$ For example, some general aspects of regio- and stereochemistry of propylene insertions for rac- $\left\{\right.$ bridge-(1-Ind) $\left.{ }_{2}\right\} \mathrm{ZrX}_{2}$ (where bridge $=\mathrm{R}_{2} \mathrm{Si}, \mathrm{R}_{2} \mathrm{C}$ or $\mathrm{C}_{2} \mathrm{H}_{4} ; \mathrm{X}=\mathrm{Cl}$, alkyl), ${ }^{3}$ in particular, $\quad r a c-\left\{\mathrm{Me}_{2} \mathrm{Si}(2-\mathrm{Me}-4-\mathrm{Ph}-\mathrm{Ind})_{2}\right\} \mathrm{ZrCl}_{2} \quad(3),{ }^{4}$ have been already studied computationally using various levels of theory. Thus, enantiomorphic site control (ESC) via ubiquitous chain migratory insertion has been corroborated as the operative mechanism for this system, which resulted in the design of new, more stereoselective $\{\mathrm{SBI}\}$-type metallocenes. $^{4 c}$

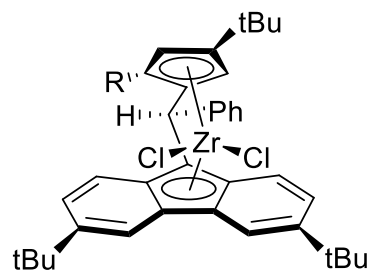

$\mathrm{R}=\mathrm{Me}(1-\mathrm{Me})$ $\mathrm{Ph}(1-\mathrm{Ph})$

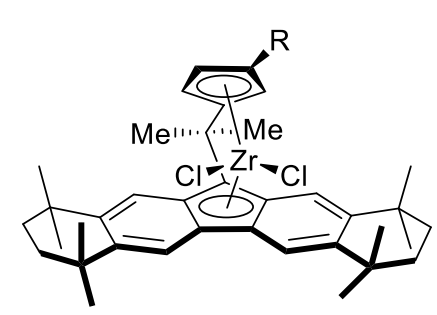

$\mathrm{R}=2-\mathrm{Me}-2$-adamantyl (2)

$C_{1}$-symmetric precatalysts

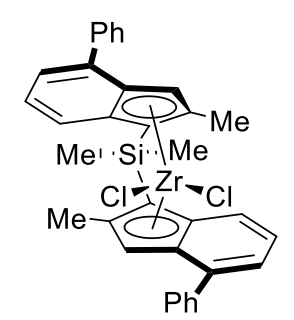

3

$C_{2}$-symmetric precatalyst

Scheme 1. Zirconocene precatalysts $\mathbf{1 - R}(\mathrm{Me}, \mathrm{Ph}), \mathbf{2}$ and $\mathbf{3}$ used as models in this study. 
On the other hand, for the $\{\mathrm{Cp} / \mathrm{Flu}\}$-type metallocenes, the situation is less obvious. While the chain migratory insertion (CMI) mechanism has been generally accepted for the syndioselective $C_{\mathrm{s}}$-symmetric systems, ${ }^{5,3 i}$ two mechanisms were hypothesized for their isoselective $C_{1}$-symmetric analogues (Scheme 2). First, chain "stationary" insertion (or site epimerization), involving monomer insertion only on the more stereoselective site, followed by site epimerization (backskip), has been suggested by Razavi et al. ${ }^{6}$ as the main operating mechanism of formation of isotactic sequences. In addition, an alternating mechanism has been proposed by Marks et al., ${ }^{7}$ which involves both a lesser and a more stereoselective sites of the molecule for monomer insertion. Bercaw et al. have discussed a case where both above mechanisms could be functioning simultaneously. ${ }^{8}$ In the latter study, metallocene precatalyst 2 that features superior isoselectivity was developed; it was proposed that this catalyst enchains propylene via solely the site epimerization (backskip) mechanism, completely suppressing the alternating one. ${ }^{8 b}$ Possible stereocontrol mechanisms for $C_{1}$-symmetric systems analogous to $\mathbf{1 - R}$ and $\mathbf{2}$ (Scheme 1) have been computationally probed by Ziegler, Razavi et al. ${ }^{9}$ and others. ${ }^{10}$ Yet, the obtained thermochemical data were found not sufficiently explicit to allow drawing straightforward conclusion on the operative stereocontrol mechanism.

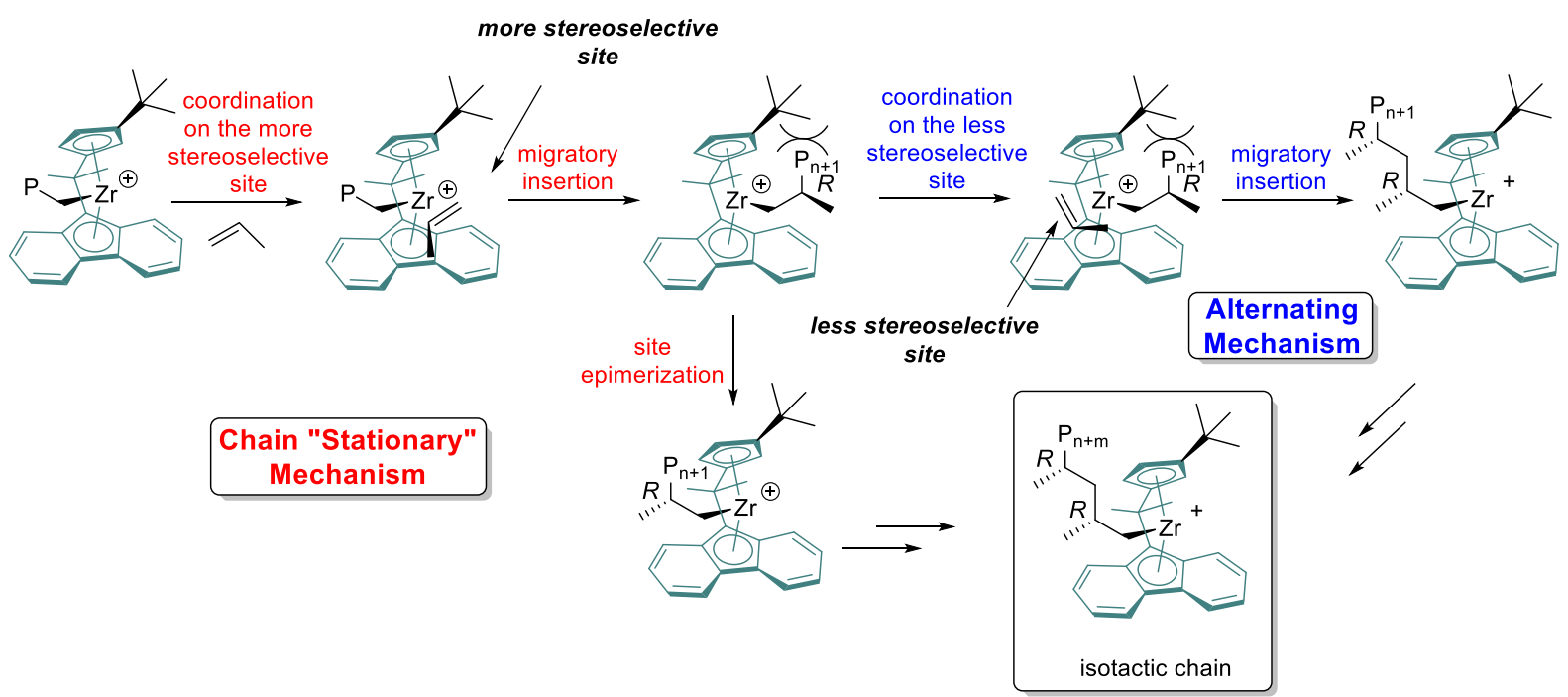

Scheme 2. Proposed mechanisms of stereocontrol with $C_{1}$-symmetric metallocene catalysts. ${ }^{8}$ 
In this study, we aimed at rationalizing the mechanism of regio- and stereocontrol of the highly isoselective polymerization of propylene with complexes $\mathbf{1}-\mathbf{R}^{11}$ and $\mathbf{2}^{8 \mathrm{~b}}$ (Scheme 1) by theoretical computations of the first, second and third insertion steps. For straight comparison and benchmarking, DFT studies on the same level of theory were employed for system 3, which is well known to operate via an enantiomorphic site control mechanism involving chain migratory insertion reactions (vide supra). ${ }^{2}$ Besides, for the above catalytic systems, a probabilistic modeling based on the procedure described by Farina et al. ${ }^{12}$ and Chien et al. ${ }^{13}$ was carried out using the computed thermochemical data; ${ }^{14}$ meso/rac pentad distributions for iPP samples obtained at various temperatures were predicted and found to be in good to acceptable consistency with experimental data.

\section{RESULTS AND DISCUSSION}

General Considerations used for Theoretical Models. It is generally accepted that ionic complexes of general structure $\left[\mathrm{Cp}_{2} \mathrm{ZrMe}\right]^{+}[\mathrm{Me}-\mathrm{MAO}]^{-}(\mathrm{Cp}=$ cyclopentadienyl-type ligand), which form during the activation step in a reaction between parent $\mathrm{Cp}_{2} \mathrm{ZrX}_{2}(\mathrm{X}=$ halogen or alkyl) and excess MAO, constitute a loosely associated form of a "true" catalyst a "naked" cation $\left[\mathrm{Cp}_{2} \mathrm{ZrMe}\right]^{+}$and the corresponding counterion $[\mathrm{Me}-\mathrm{MAO}]^{-} .{ }^{15,16}$ Although different theoretical models treating complex systems incorporating molecular versions of anions such as $\left[\mathrm{MeB}\left(\mathrm{C}_{6} \mathrm{~F}_{5}\right)_{3}\right]^{-},\left[\mathrm{B}\left(\mathrm{C}_{6} \mathrm{~F}_{5}\right)_{4}\right]^{-}$, and $\left[\mathrm{Me}\left\{\mathrm{MeAl}\left(\mu_{3}-\mathrm{O}\right)\right\}_{3}\right]^{-}$were generally successful, ${ }^{17}$ implementation of the MAO-based anion in the calculations is still problematic; this is due to the unclear and controversial structure of MAO, its dynamic behavior ${ }^{18}$ and obvious computational costs related to the large structure of this system. The nature of the counterion may play a significant role in stereochemistry of propylene insertion, namely, influencing the propagation, site epimerization (backskip) and misinsertion kinetics. ${ }^{5 b, 19}$ At the same time, the direct influence of the counterion is neglected in many theoretical models 
applied to stereochemistry computations. ${ }^{14,20}$ This can be rationalized in the view of the following two possible phenomena: (1) in case of tightly bound ion pairs incorporating strongly coordinating counterions (e.g., $\left.\left[\mathrm{MeB}\left(\mathrm{C}_{6} \mathrm{~F}_{5}\right)_{3}\right]^{-}\right)$, extraction and substitution of the counterion upon coordination of a monomer molecule is an endothermic process, which activation barrier magnitude will be barely independent of the site involved in coordination; ${ }^{9 \mathrm{c}}$ (2) in late polymerization steps, the growing polymer chain may expulse the counterion on some distance from the coordination site, thus making its further involvement minimal.

In a recent contribution, we have developed a DFT theoretical model competent for quantitatively describing propylene insertion into metal-alkyl bonds of neutral and cationic metallocenes including the "naked" cation $\left[\left\{\mathrm{Ph}(\mathrm{H}) \mathrm{C}\left(3,6-t \mathrm{Bu}_{2}-\mathrm{Flu}\right)(3-t \mathrm{Bu}-5-\mathrm{Me}-\mathrm{Cp})\right\} \mathrm{ZrMe}\right]^{+}$ derived from 1-Me. ${ }^{21}$ In this model, $\Delta H / \Delta H^{\#}$ values are calculated, which were shown for a binary system involving bis(cyclopentadienyl)yttrium alkyl and propylene for which experimental data are available, to be very close to the corresponding $\Delta G / \Delta G^{\#}$ values calculated using both dispersion correction and SMD solvation model. This DFT model (see SI) has been used throughout this study for all computations.

In order to assess the regio- and stereoselectivities of catalysts, all possible mechanisms of monomer insertion were considered. First, two main types of insertions are possible: the primary $(1,2-; \mathrm{pr})$ and secondary $(2,1-$; sec $)$ insertions, which lead, for the first polymerization step, to iso-butyl and sec-butyl products $(\mathrm{R}=\mathrm{Me})$, respectively (Scheme 3).

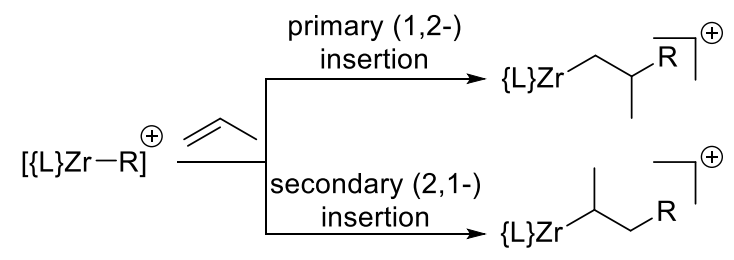

Scheme 3. Primary and secondary insertions of propylene into $\mathrm{Zr}-\mathrm{R}$ bond. 
Second, eight different insertion reactions have to be considered for $C_{1}$-symmetric systems 1-R and 2, as depicted in Scheme 4. Indeed, these systems can adopt two different configurations, as the $\mathrm{Zr}$-polymeryl chain can reside either in anti or syn orientation with respect to the $t \mathrm{Bu}$ group of the $\mathrm{Cp}$ ligand (these two possibilities are hereafter denoted as $\mathrm{A}$ and $\mathrm{S}$, respectively). Moreover, the propylene molecule can insert into the $\mathrm{Zr}-\mathrm{C}$ (polymeryl) bond via either the re or si face. Hence, for example, primary insertion si into the anti isomer of 1-R and $\mathbf{2}$ will be noted as A-pr-si. It is noteworthy that for insertion into the anti isomer, propylene binds at the more crowded site of the catalyst (i.e., the one accommodating the $t \mathrm{Bu}-$ Cp substituent) and that the resulting product will use in turn the syn coordination site for the forthcoming insertion step. Correspondingly, for the insertion into the syn isomer, propylene coordinates at the less crowded site and the resulting product will use the anti coordination site. For the $C_{2}$-symmetric system $\mathbf{3}$, only four different insertions, namely pr-si, pr-re, sec-si and sec-re, have to be considered.

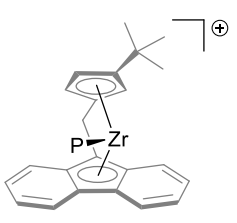

Anti-tBu,P

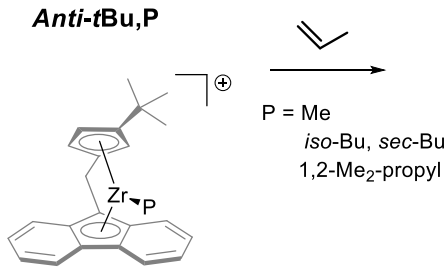

Syn-tBu,P
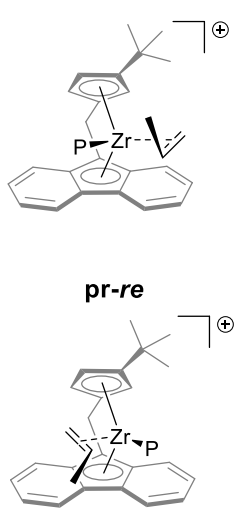
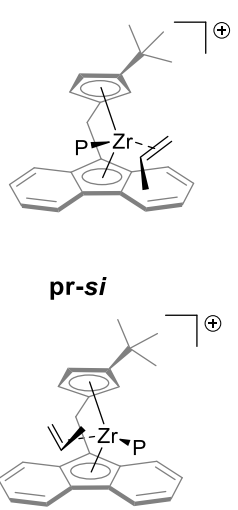
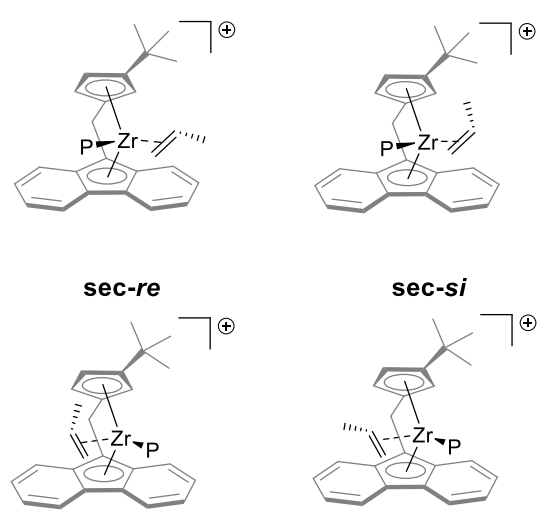

Scheme 4. Eight possible propylene $\pi$-adducts of cationic complexes for $C_{1}$-symmetric $\{\mathrm{Cp} / \mathrm{Flu}\}$ metallocene catalysts. 
$C_{1}$-Symmetric Systems. Energetic data for the three consecutive propylene insertion steps for the cationic precursor $\left[\left\{\mathrm{Ph}(\mathrm{H}) \mathrm{C}\left(3,6-t \mathrm{Bu}_{2}-\mathrm{Flu}\right)(3-t \mathrm{Bu}-5-\mathrm{Me}-\mathrm{Cp})\right\} \mathrm{ZrMe}\right]^{+}$(1-Me) were calculated (Table 1), and eight possible pathways via the formation of the corresponding propylene $\pi$-adducts were considered at each insertion step. For the 5-Ph-Cp-substituted analogue $\left[\left\{\mathrm{Ph}(\mathrm{H}) \mathrm{C}\left(3,6-t \mathrm{Bu}_{2}-\mathrm{Flu}\right)(3-\mathrm{BBu}-5-\mathrm{Ph}-\mathrm{Cp})\right\} \mathrm{ZrMe}^{+}\right.$(1-Ph) only the second insertion step was computed, and for the significantly bulkier $\left[\left\{\mathrm{Me}_{2} \mathrm{C}(\mathrm{Oct})(3-(2-\mathrm{methy} 1-2-\right.\right.$ adamanthyl)-Cp) $\} \mathrm{ZrMe}]^{+}$(2), only the second and the third insertion steps were calculated. For each insertion step, the zero of energy corresponds to the anti isomer of the "naked" cation (more stable than the syn isomer by $2.5 \mathrm{kcal} . \mathrm{mol}^{-1}$ for the very first insertion step) and a propylene molecule on an infinite distance (Fig. 1).

On the basis of the results obtained for systems $\mathbf{1 - R}(\mathrm{R}=\mathrm{Me}, \mathrm{Ph})$ and $\mathbf{2}$, the following trends can be highlighted:

1) Regardless the actual monomer insertion step, primary (1,2-) coordination and insertion of propylene into $\mathrm{Zr}-\mathrm{C}(\mathrm{alkyl})$ bond are systematically highly selective for both systems, which is evidenced from the corresponding lower activation barriers (typically by $3-11$ $\left.\mathrm{kcal} \cdot \mathrm{mol}^{-1}\right)$ than those calculated for secondary $(2,1-)$ insertions. This appears to be driven in part by steric considerations. For example, the corresponding optimized structures of the transition states for the primary insertions in 1-Me (Fig. S2) revealed no particular steric repulsion between the methyl group of the coordinated propylene molecule and the ligand system, while those for the secondary insertions feature strong steric hindrance imposed by the ligand system. Also, the $\mathrm{Zr}-i \mathrm{Bu}$ and higher $\mathrm{Zr}-$ polymeryl products resulting from the 1,2-insertions are more thermodynamically stable; this apparently stems from the presence of $\beta-\mathrm{C}-\mathrm{H} \cdots \mathrm{Zr}$ agostic interactions (Fig. 1) stabilizing the cationic center. ${ }^{22}$ 

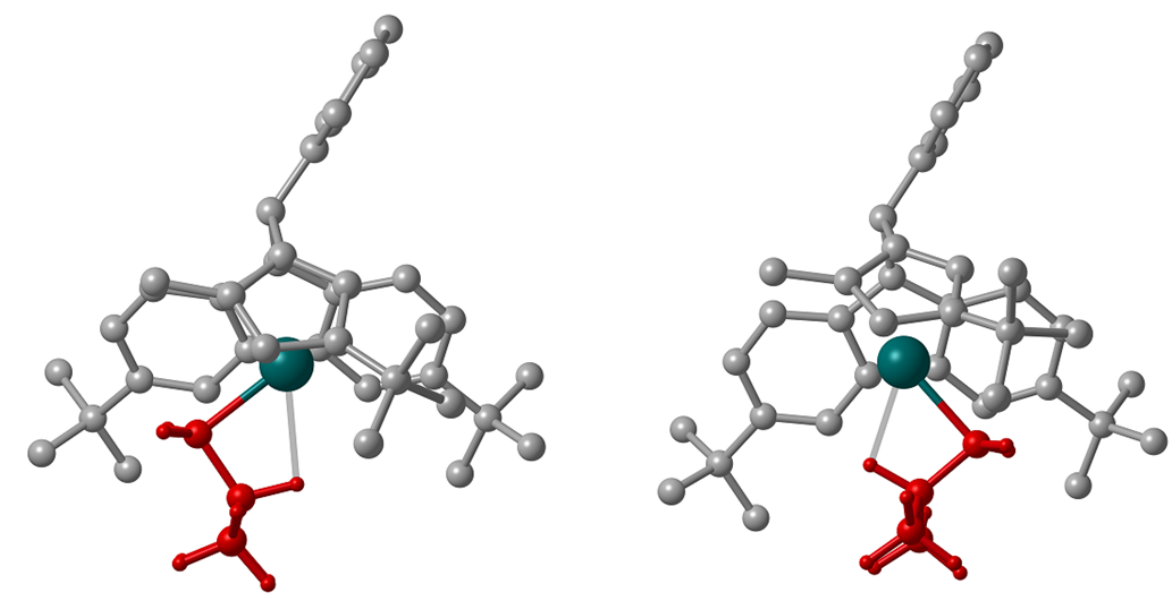

Figure 1. Optimized geometries of anti (left) and syn (right) isomers of the iso-butyl product of 1-Me. Hydrogen atoms of the $\mathrm{Cp}$ and Flu moieties and those of the entire $\mathrm{C}(\mathrm{Ph}) \mathrm{H}$ bridge are omitted for clarity. The iso-butyl group is depicted in red.

2) As demonstrated for 1-Me, the very first propylene insertion into $\mathrm{Zr}-\mathrm{Me}$ bond is not stereoselective. Indeed, all four primary insertion reactions feature very close barriers $\left(7.1-8.5 \mathrm{kcal} \cdot \mathrm{mol}^{-1}\right)$ and afford thermodynamically stable (by 14.6 and $17.7 \mathrm{kcal} \cdot \mathrm{mol}^{-1}$ ) products (Fig. 1).

3) Stereoselectivity control over monomer insertion for the $C_{1}$-symmetric system 1-Me comes out from the second insertion step, that is propylene insertion in the $\mathrm{Zr}-\mathrm{C}(i \mathrm{Bu})$ bond. $^{23}$ First of all, in agreement with the mechanism of Razavi et al., ${ }^{6,9 \mathrm{~d}, 8}$ A-pr-si insertion of propylene on the crowded site ("head down" into the free space of the central region of the fluorenyl ligand) is the preferred one in terms of kinetics. Also, the energy differences between the propylene insertion barriers for A-pr-re and A-pr-si computed for the second and third insertion steps $\left(\Delta \Delta H^{\neq}=4.6\right.$ and $3.9 \mathrm{kcal} \cdot \mathrm{mol}^{-1}$, respectively) suggest that an enantiofacial misinsertion is kinetically disfavored on the crowded site. As expected, the open site of the metallocene is significantly less selective: small energy differences $\left(<1 \mathrm{kcal} \cdot \mathrm{mol}^{-1}\right)$ between the barriers of the S-pr-re 
and S-pr-si insertions of propylene were calculated for the second and third insertion reactions.

Second, the iso-butyl and the higher products formed after the S-pr-si and S-pr-re second and third insertions, respectively, are more stable by $3-5 \mathrm{kcal} \cdot \mathrm{mol}^{-1}$ than their counterparts formed after the A-pr-si and A-pr-re insertions. This difference is due to the relative positioning of the $i \mathrm{Bu}$ (or polymeryl) groups with respect to the $t \mathrm{Bu}$ substituent of the Cp moiety - anti for the S-pr-re and S-pr-si insertions products and syn for the A-pr-re and A-pr-si ones (Fig. 2).

Overall, these results suggest that, after the stereoselective A-pr-si insertion, the resulted constrained syn product with the propagating chain initially residing on the crowded site should rearrange via epimerization (Scheme 5) to a less sterically congested, more stable (by ca. $4 \mathrm{kcal} \cdot \mathrm{mol}^{-1}$ ) anti isomer. ${ }^{24}$ This sequence of insertionepimerization steps leads to the formation of iPP by a stationary propagation, i.e. a chain "stationary" insertion mechanism. ${ }^{6}$

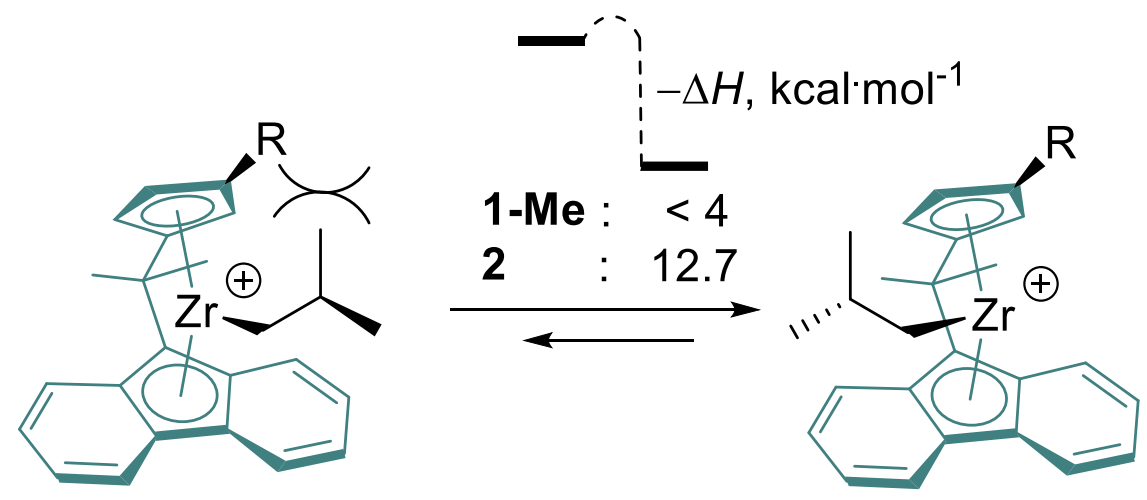

Scheme 5. Epimerization (backskip) process for $C_{1}$-symmetric $\{\mathrm{Cp} / \mathrm{Flu}\}$ metallocene catalysts. 


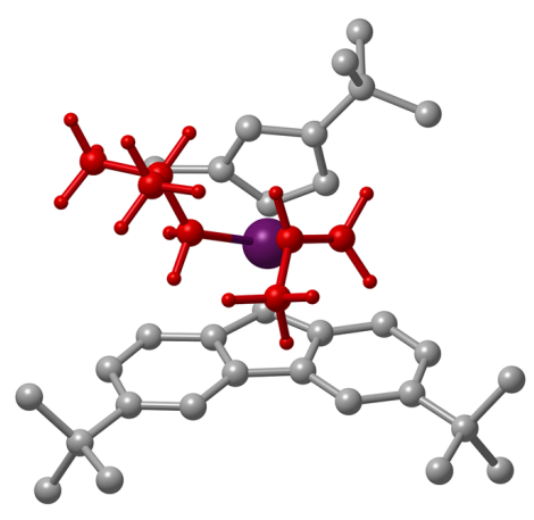

A-pr-si

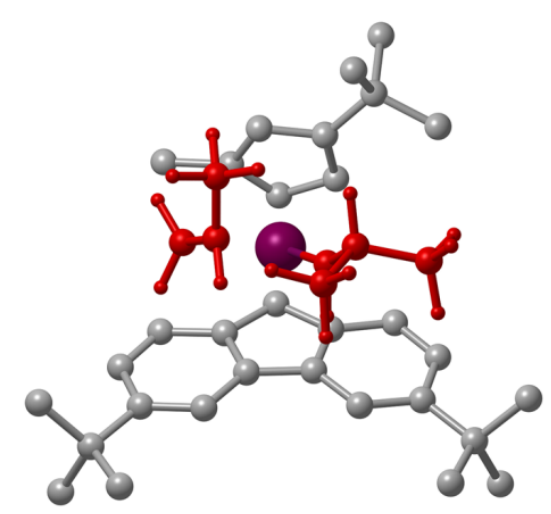

S-pr-si

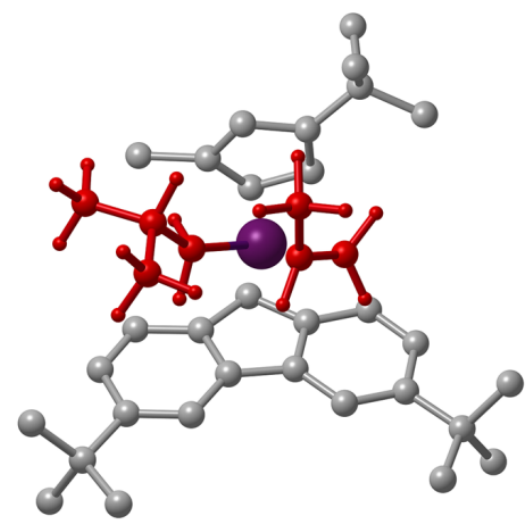

A-pr-re

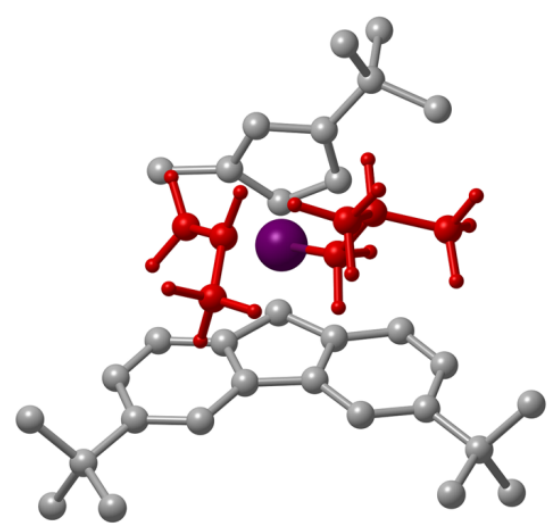

S-pr-re

Figure 2. Optimized transition state geometries for the second insertion of propylene. Hydrogen atoms of the $\mathrm{Cp}$ and Flu moieties and those of the entire $\mathrm{C}(\mathrm{Ph}) \mathrm{H}$ bridge are omitted for clarity. The propylene molecule and the iso-butyl group are depicted in red.

4) The data computed for the second insertion step with system 1-Ph (Table 1) are also in complete agreement with the epimerization mechanism. Yet, the 1-Ph system is computed to be less stereoselective than 1-Me, due to the smaller energy difference between the barriers of misinsertion A-pr-re and stereoselective A-pr-si insertion $\left(\Delta \Delta H^{\neq}\right.$ $\left.=3.1 \mathrm{kcal} \cdot \mathrm{mol}^{-1}\right)$. Also, the higher propylene A-pr-si insertion barrier calculated for 1$\mathbf{P h}\left(\Delta \Delta H^{\ddagger}=1.5 \mathrm{kcal} \cdot \mathrm{mol}^{-1}\right)$ calls for a lower polymerization activity than that observed 
for 1-Me. Both DFT results are in agreement with our experimental findings for these systems. ${ }^{11}$

5) For system $\mathbf{2}$, only one stable propylene adduct, namely S-pr-re (and the corresponding transition state for insertion reaction), was located for the third insertion step, whereas for other adducts, optimizations resulted in each case in the corresponding "naked" cation anti-(2-Me-2-adamantyl),polymeryl and a dissociated propylene molecule. More, epimerization of the A-pr-si insertion product to that of the S-pr-re insertion (Scheme 5) via presumably a very low-energy transition state ${ }^{24}$ is much more favored by thermodynamics (by $12.7 \mathrm{kcal} \cdot \mathrm{mol}^{-1}$ ) than that calculated for the 1-Me system (vide supra). The latter result and also the fact that the S-pr-re insertion features a much less stable propylene adduct $\left(+13.3 \mathrm{kcal} \cdot \mathrm{mol}^{-1}\right)$ and a higher by energy transition state $(17.6$ $\mathrm{kcal} \cdot \mathrm{mol}^{-1}$ ) both suggest that the only stereocontrol mechanism operating for this system is via chain "stationary" insertion.

Using the three-parameter probabilistic model for $C_{1}$-symmetric systems described by Farina et al. (see the SI), ${ }^{12}$ we have predicted meso/rac distributions from the computed insertion enthalpy values (Table 2). This model appeared to be competent to estimate (within acceptable margins) pentad distributions at different temperatures. For example, for 1-Me, the model reproduces very well the results obtained at lower polymerization temperature (60$70{ }^{\circ} \mathrm{C}$ ), while at higher temperature $\left(100^{\circ} \mathrm{C}\right)$ the deviation (quadratic mean, RMS) was found higher. Apparently, the latter discrepancy can be a result of a higher amount of regioerrors (issued from secondary insertions) formed at higher temperature and whose account cannot be included in the given probabilistic model. ${ }^{25}$ A similar trend was obtained for system 1-Ph (Table 3), yet with more significant discrepancy between the experimental and simulated results at higher polymerization temperatures. Of note, a much lower regioregularity (primary 
insertions $=91.8 \%$ ) was determined experimentally in PPs produced with this system at higher polymerization temperature $\left(\mathrm{T}_{\text {pol }}=100^{\circ} \mathrm{C}\right)$.

The DFT calculated probabilistic descriptors $\boldsymbol{a}, \boldsymbol{b}$ and $\boldsymbol{k}$ are all consistent with general isoselective behavior of the studied metallocene systems. The near-one calculated values of descriptors $\boldsymbol{b}$ and $\boldsymbol{k}$ are consistent with the site epimerization mechanism of Razavi et $a .^{6}$ when, after isoselective insertion on the crowded site, the propagating chain immediately migrates to the open site of the catalyst. On the other hand, the relatively high value of $\boldsymbol{a}$ (along with inequality of the $(1-\boldsymbol{k})$ descriptor to 0$)$ is diagnostic that the stereocontrol alternating mechanism, ${ }^{8}$ in which propylene insertion occurs on the lesser stereoselective open site, may also be valid for that given system. Both results are in line with the general assumption by Bercaw et al. ${ }^{8}$ that both alternating and site epimerization mechanisms of stereocontrol can operate simultaneously for one and the same catalyst. More, the predominance of the more selective chain "stationary" mechanism over the less selective alternating one for this particular metallocene system is essentially determined by the steric hindrance of the 3-cyclopentadienyl substituent and, to a lesser extent, of the substituents on the fluorenyl ligand. Thus, the bulkier the 3-cyclopentadienyl substituent (e.g., 2-methyl-2adamantyl $>>t \mathrm{Bu}>>\mathrm{Me}$ ), the higher the stereocontrol via chain migratory mechanism and the lower the role of the alternating mechanism. The latter aspect is clearly demonstrated on system 2, which features the highest degree of stereocontrol in terms of $\left[\mathrm{m}^{4}\right]$ pentads content (>99\%) among $C_{1}$-symmetric $\{\mathrm{Cp} / \mathrm{Flu}\}$ catalysts. ${ }^{8 \mathrm{~b}}$ In this case, the "stationary" stereocontrol mechanism is consistent with instant site "epimerization" $(\boldsymbol{k}=1)$ realized after a stereoselective $(\boldsymbol{b} \rightarrow 1)$ monomer insertion on the more stereoselective (crowded) site, while the stereoselectivity of the lesser stereoselective (open) site (not used for the coordination) has utterly no influence $(0<\boldsymbol{a}<1)$. 
Table 1. Energetic data calculated for different insertion steps of propylene for systems $\mathbf{1 - R}(\mathrm{R}=\mathrm{Me}, \mathrm{Ph})$ and $\mathbf{2}^{a}$

\begin{tabular}{|c|c|c|c|c|c|c|c|}
\hline \multirow[b]{2}{*}{ Reaction } & & \multicolumn{3}{|c|}{ 1-Мe } & \multirow{2}{*}{$\begin{array}{c}\mathbf{1 - P h} \\
\Delta H \\
\left(2^{\text {nd }} \text { insertion }\right)\end{array}$} & \multicolumn{2}{|c|}{2} \\
\hline & & $\begin{array}{c}\Delta H \\
\left(1^{\text {st }} \text { insertion }\right)\end{array}$ & $\begin{array}{c}\Delta H \\
\left(2^{\text {nd }} \text { insertion }\right)\end{array}$ & $\begin{array}{c}\Delta H \\
\left(3^{\mathrm{d}} \text { insertion) }\right.\end{array}$ & & $\begin{array}{c}\Delta H \\
\left(2^{\text {nd }} \text { insertion }\right)\end{array}$ & $\begin{array}{c}\Delta H \\
\text { (3 } 3^{\mathrm{d}} \text { insertion) }\end{array}$ \\
\hline A-pr-si & $\begin{array}{c}\text { Adduct } \\
\text { TS } \\
\text { Product }\end{array}$ & $\begin{array}{c}-3.4 \\
8.6 \\
-14.6 \\
\end{array}$ & $\begin{array}{c}1.7 \\
10.4 \\
-13.5 \\
\end{array}$ & $\begin{array}{c}0.9 \\
10.0 \\
-14.5 \\
\end{array}$ & $\begin{array}{c}2.6 \\
11.9 \\
-13.2 \\
\end{array}$ & $\begin{array}{c}6.9 \\
15.9 \\
-5.5 \\
\end{array}$ & $\begin{array}{c}3.3 \\
15.6 \\
-6.3 \\
\end{array}$ \\
\hline A-pr-re & $\begin{array}{c}\text { Adduct } \\
\text { TS } \\
\text { Product }\end{array}$ & $\begin{array}{c}-3.1 \\
8.5 \\
-14.6 \\
\end{array}$ & $\begin{array}{c}2.1 \\
15.0 \\
-14.2 \\
\end{array}$ & $\begin{array}{c}2.1 \\
13.9 \\
-14.4 \\
\end{array}$ & $\begin{array}{c}3.6 \\
15.0 \\
-16.9 \\
\end{array}$ & $\begin{array}{c}3.9 \\
18.4 \\
-9.3 \\
\end{array}$ & $\begin{array}{r}7.0 \\
19.3 \\
-9.3\end{array}$ \\
\hline A-sec-si & $\begin{array}{l}\text { Adduct } \\
\text { TS } \\
\text { Product }\end{array}$ & $\begin{array}{r}-0.6 \\
18.8 \\
-1.5 \\
\end{array}$ & $\begin{array}{c}3.9 \\
21.0 \\
-6.6\end{array}$ & $\begin{array}{c}6.2 \\
22.0 \\
-7.4\end{array}$ & $\begin{array}{c}5.3 \\
21.3 \\
-5.6\end{array}$ & n.l. & 1. \\
\hline A-sec-re & $\begin{array}{c}\text { Adduct } \\
\text { TS } \\
\text { Product }\end{array}$ & $\begin{array}{r}0.2 \\
15.9 \\
-4.2 \\
\end{array}$ & $\begin{array}{c}5.3 \\
17.5 \\
-6.5 \\
\end{array}$ & $\begin{array}{r}4.0 \\
18.9 \\
-6.0 \\
\end{array}$ & $\begin{array}{c}6.8 \\
19.2 \\
-8.0 \\
\end{array}$ & n.1. & \\
\hline S-pr-si & $\begin{array}{l}\text { Adduct } \\
\text { TS } \\
\text { Product }\end{array}$ & $\begin{array}{c}-3.6 \\
7.2 \\
-17.7\end{array}$ & $\begin{array}{c}4.1 \\
13.5 \\
-18.1\end{array}$ & $\begin{array}{c}9.9 \\
12.6 \\
-18.8\end{array}$ & $\begin{array}{c}4.1 \\
13.3 \\
-14.4\end{array}$ & n.1. & \\
\hline S-pr-re & $\begin{array}{c}\text { Adduct } \\
\text { TS } \\
\text { Product }\end{array}$ & $\begin{array}{c}-4.3 \\
7.1 \\
-17.7 \\
\end{array}$ & $\begin{array}{c}7.6 \\
14.0 \\
-17.2 \\
\end{array}$ & $\begin{array}{c}8.3 \\
13.4 \\
-17.8 \\
\end{array}$ & $\begin{array}{c}7.3 \\
14.2 \\
-15.5 \\
\end{array}$ & n.c. & \begin{tabular}{|l}
3.3 \\
7.6 \\
19.0 \\
\end{tabular} \\
\hline S-sec-si & $\begin{array}{l}\text { Adduct } \\
\text { TS } \\
\text { Product }\end{array}$ & $\begin{array}{l}-3.2 \\
15.1 \\
-5.9\end{array}$ & $\begin{array}{c}7.7 \\
19.3 \\
-9.8\end{array}$ & $\begin{array}{c}8.5 \\
19.1 \\
-10.8\end{array}$ & $\begin{array}{c}6.1 \\
17.9 \\
-9.5\end{array}$ & n.l. & \\
\hline S-sec-re & $\begin{array}{c}\text { Adduct } \\
\text { TS } \\
\text { Product }\end{array}$ & $\begin{array}{l}-2.6 \\
11.8 \\
-9.6\end{array}$ & $\begin{array}{c}4.7 \\
15.7 \\
-11.3\end{array}$ & $\begin{array}{c}4.4 \\
15.2 \\
-13.8\end{array}$ & $\begin{array}{c}5.3 \\
17.6 \\
-11.1\end{array}$ & n.l. & \\
\hline
\end{tabular}

\footnotetext{
${ }^{a}$ The values for the insertion barriers were calculated as $\Delta H^{+}$ins $=H_{\mathrm{TS}}-H_{\text {Reactant. }}{ }^{b}$ The corresponding TS geometries were not located (n.l.) or not calculated (n.c.).
} 
Table 2. Pentad distributions (\%) and corresponding probability parameters ${ }^{12}$ determined experimentally for 1-Me, and those simulated using a three-parameter model and DFT computation data. ${ }^{a}$

\begin{tabular}{|c|c|c|c|c|c|c|c|c|c|c|}
\hline & \multirow{3}{*}{$\begin{array}{c}\text { Exp } \\
60\end{array}$} & \multirow{3}{*}{$\begin{array}{c}\text { Calc } \\
- \\
\end{array}$} & \multirow{3}{*}{$\frac{\text { Exp }}{100}$} & \multirow{3}{*}{$\frac{\text { Calc }}{-}$} & \multicolumn{6}{|c|}{ Calculated from DFT data } \\
\hline & & & & & \multicolumn{3}{|c|}{$2^{\text {nd }}$ insertion } & \multicolumn{3}{|c|}{$3^{\mathrm{d}}$ insertion } \\
\hline & & & & & 25 & 70 & 100 & 25 & 70 & 100 \\
\hline$M_{\mathbf{n}}\left[\times 10^{3}\right]$ & 54.8 & - & 6.8 & - & & & & & & \\
\hline 1,2 ins & nd & - & 98.6 & - & - & - & - & - & - & - \\
\hline$[\mathrm{mmmm}]$ & 91.6 & 91.6 & 53.3 & 53.4 & 97.0 & 93.5 & 90.4 & 94.9 & 90.0 & 85.9 \\
\hline [mmmr] & 3.1 & 3.0 & 14.5 & 14.3 & 0.9 & 1.8 & 2.7 & 1.6 & 3.1 & 4.2 \\
\hline [rmmr] & 0.2 & 0.1 & 1.5 & 1.1 & 0.1 & 0.2 & 0.3 & 0.1 & 0.2 & $0.3-1$ \\
\hline [mmrr] & 2.8 & 2.9 & 14.6 & 14.3 & 0.7 & 1.5 & 2.2 & 1.5 & 2.8 & $3.9=$ \\
\hline $\begin{array}{l}\text { [mrmm] } \\
+[\mathrm{rmrr}]\end{array}$ & 0.4 & 0.4 & 3.9 & 4.3 & 0.5 & 1.1 & 1.6 & 0.5 & 1.2 & 1.7 \\
\hline [mrmr] & 0.1 & 0.2 & 1.6 & 2.2 & 0.2 & 0.5 & 0.8 & 0.3 & 0.6 & 0.5 \\
\hline [rrrr] & 0.1 & 0.1 & 1.2 & 1.1 & 0.1 & 0.2 & 0.3 & 0.1 & 0.2 & 0.4 \\
\hline [mrrr $]$ & 0.1 & 0.2 & 2.0 & 2.2 & 0.2 & 0.5 & 0.7 & 0.3 & 0.5 & 0.8 \\
\hline [mrrm] & 1.5 & 1.5 & 7.5 & 7.2 & 0.3 & 0.7 & 1.0 & 0.7 & 1.4 & 1.9 \\
\hline total & 100.0 & 100.0 & 100.0 & 100.0 & 100.0 & 100.0 & 100.0 & 100.0 & 100.0 & $100 . \Omega$ \\
\hline $\mathbf{R M S}^{b}$ & - & 0.09 & - & 0.34 & - & 0.96 & 13.82 & - & 0.63 & 12.13 \\
\hline$a^{c}$ & & 0.8613 & & 0.8810 & 0.6994 & 0.6756 & 0.6625 & 0.7943 & 0.7638 & $0.746+$ \\
\hline $\boldsymbol{b}^{c}$ & & 0.9912 & & 0.8827 & 0.9996 & 0.9988 & 0.9980 & 0.9986 & 0.9967 & 0.9943 \\
\hline $\boldsymbol{k}^{c}$ & & 0.9790 & & 0.8000 & 0.9925 & 0.9846 & 0.9775 & 0.9847 & 0.9720 & $0.961 \mathrm{~S}$ \\
\hline
\end{tabular}

${ }^{a}$ Experimental data taken from ref. 11; $\boldsymbol{a}$ and $\boldsymbol{b}$ - the probabilities of stereoselective insertion on the open and crowded metallocene faces, respectively; $\boldsymbol{k}$ - the probability of site epimerization. ${ }^{b} R M S=\left(\left(\sum\left(I_{\text {obs }}-I_{\text {calc }}\right)^{2} / 9\right)^{0.5}\right.$. ${ }^{c}$ Calculated as: $\frac{a}{1-a}=$ $e^{-\frac{\left(H_{S-p r-s i}-H_{S-p r-r e}\right)}{R T}} ; \frac{b}{1-b}=e^{-\frac{\left(H_{A-p r-s i}{ }^{-} H_{A-p r-r e}\right)}{R T}}$ and $\frac{b k}{(1-b)(1-k)}=e^{-\frac{\left(H_{A-p r-s i} H_{S-p r-s i}\right)}{R T}}$. 
Table 3. Pentad distributions (\%) and corresponding probability parameters ${ }^{12}$ determined experimentally for 1-Ph, and those simulated using a three-parameter model and DFT computation data. ${ }^{a}$

\begin{tabular}{|c|c|c|c|c|c|c|c|c|c|c|}
\hline \multirow{3}{*}{$\mathrm{T},\left[{ }^{\circ} \mathrm{C}\right]$} & & & & & & & \multirow{2}{*}{\multicolumn{4}{|c|}{$\begin{array}{c}\text { Calculated from DFT data } \\
2^{\text {nd }} \text { insertion } \\
\end{array}$}} \\
\hline & Exp & Calc & Exp & Calc & Exp & Calc & & & & \\
\hline & \multicolumn{2}{|c|}{60} & \multicolumn{2}{|c|}{80} & \multicolumn{2}{|c|}{100} & 25 & 60 & 80 & 100 \\
\hline$M_{\mathbf{n}}\left[\times 10^{3}\right]$ & 8.6 & - & 6.1 & - & 1.8 & - & & & & \\
\hline 1,2 ins & 97.7 & - & 99.1 & - & 91.8 & - & - & - & - & - \\
\hline$[\mathrm{mmmm}]$ & 48.5 & 48.6 & 20.2 & 21.7 & 4.3 & 6.3 & 78.0 & 71.2 & 67.4 & 63.9 \\
\hline$[\mathrm{mmmr}]$ & 15.2 & 15.1 & 15.8 & 16.2 & 8.3 & 12.5 & 6.9 & 8.8 & 9.7 & 10.6 \\
\hline$[r m m r]$ & 1.7 & 1.4 & 4.0 & 3.8 & 5.7 & 6.2 & 0.3 & 0.5 & 0.6 & 0.7 \\
\hline [mmrr] & 15.8 & 15.1 & 18.3 & 16.2 & 12.5 & 12.5 & 6.8 & 8.7 & 9.6 & 10.5 \\
\hline $\begin{array}{l}{[m r m m]} \\
+[r m r r]\end{array}$ & 4.6 & 5.4 & 13.2 & 15.1 & 22.1 & 25.0 & 2.0 & 2.9 & 3.5 & 4.0 \\
\hline [mrmr] & 1.9 & 2.7 & 6.0 & 7.6 & 11.8 & 12.5 & 1.1 & 1.6 & 1.9 & 2.2 \\
\hline [rrrr] & 1.6 & 1.4 & 5.3 & 3.8 & 11.7 & 6.2 & 0.5 & 0.7 & 0.8 & 0.9 \\
\hline [mrrr $]$ & 2.6 & 2.7 & 7.3 & 7.6 & 14.4 & 12.5 & 1.0 & 1.4 & 1.6 & 1.9 \\
\hline$[\mathrm{mrrm}]$ & 8.1 & 7.6 & 10.0 & 8.1 & 9.3 & 6.3 & 3.4 & 4.3 & 4.8 & 5.2 \\
\hline total & 100.0 & 100.0 & 100.0 & 100.0 & 100.0 & 100.0 & 100.0 & 100.0 & 100.0 & 100.0 \\
\hline $\mathbf{R M S}^{b}$ & - & 0.49 & - & 1.44 & - & 2.83 & - & 8.34 & 16.81 & 21.85 \\
\hline$a^{c}$ & & 0.8618 & & 0.7336 & & 0.5000 & 0.8205 & 0.7958 & 0.7830 & 0.7711 \\
\hline $\boldsymbol{b}^{c}$ & & 0.8676 & & 0.7374 & & 0.5000 & 0.9947 & 0.9909 & 0.9881 & 0.9850 \\
\hline $\boldsymbol{k}^{c}$ & & 0.8733 & & 0.8515 & & 0.9216 & 0.8977 & 0.8695 & 0.8536 & 0.8381 \\
\hline
\end{tabular}

${ }^{a}$ Experimental data taken from ref. $11 ; \boldsymbol{a}$ and $\boldsymbol{b}$ - the probabilities of stereoselective insertion on the open and crowded metallocene faces, respectively; $\boldsymbol{k}$ - the probability of site "epimerization". ${ }^{b} R M S=\left(\left(\Sigma\left(I_{o b s}-I_{\text {calc }}\right)^{2} / 9\right)^{0.5} .{ }^{c}\right.$ Calculated as: $\frac{a}{1-a}=e^{-\frac{\left(H_{S-p r-s i}-H_{S-p r-r e}\right)}{R T}} ; \frac{b}{1-b}=e^{-\frac{\left(H_{A-p r-s i}{ }^{-} H_{A-p r-r e}\right)}{R T}}$ and $\frac{b k}{(1-b)(1-k)}=e^{-\frac{\left(H_{A-p r-s i}{ }^{-H} S-p r-s i\right.}{R T}}$ 
Table 4. Pentad distributions (\%) and corresponding probability parameters ${ }^{12}$ determined experimentally ${ }^{8 b}$ for 2 , and those simulated using a three-parameter model and DFT computation data. ${ }^{a}$

\begin{tabular}{|c|c|c|c|c|c|c|c|}
\hline \multirow[b]{3}{*}{$\mathrm{T},\left[{ }^{\circ} \mathrm{C}\right]$} & & & & \multicolumn{4}{|c|}{ Calculated from DFT data } \\
\hline & \multicolumn{2}{|c|}{ Exp } & \multirow[t]{2}{*}{ Calc } & \multicolumn{2}{|c|}{$2^{\text {nd }}$ insertion } & \multicolumn{2}{|c|}{$3^{\mathrm{d}}$ insertion } \\
\hline & 0 & 20 & & 0 & 20 & 0 & 20 \\
\hline$M_{\mathbf{n}}\left[\times 10^{3}\right]$ & 370 & 425 & - & & & & \\
\hline 1,2 ins & \multicolumn{2}{|c|}{ n.d. } & - & - & - & - & - \\
\hline$[\mathrm{mmmm}]$ & $>99$ & $>99$ & 99.0 & 97.7 & 96.6 & 99.5 & 99.2 \\
\hline$[\mathrm{mmmr}]$ & n.d. & n.d. & 0.4 & 0.9 & 1.3 & 0.2 & 0.3 \\
\hline$[r m m r]$ & n.d. & n.d. & 0.0 & 0.0 & 0.0 & 0.0 & 0.0 \\
\hline$[m m r r]$ & n.d. & n.d. & 0.4 & 0.9 & 1.3 & 0.2 & 0.3 \\
\hline $\begin{array}{l}{[\mathrm{mrmm}]} \\
+[\mathrm{rmrr}]\end{array}$ & n.d. & n.d. & 0.0 & 0.0 & 0.0 & 0.0 & 0.0 \\
\hline$[m r m r]$ & n.d. & n.d. & 0.0 & 0.0 & 0.0 & 0.0 & 0.0 \\
\hline [rrrrr] & n.d. & n.d. & 0.0 & 0.0 & 0.0 & 0.0 & 0.0 \\
\hline [mrrr $]$ & n.d. & n.d. & 0.0 & 0.0 & 0.0 & 0.0 & 0.0 \\
\hline$[\mathrm{mrrm}]$ & n.d. & n.d. & 0.2 & 0.5 & 0.7 & 0.1 & 0.2 \\
\hline total & - & - & 100.0 & 100.0 & 100.0 & 100.0 & 100.0 \\
\hline RMS & - & - & - & - & - & - & - \\
\hline$a^{c}$ & & & $0-1$ & & 0 & & \\
\hline $\boldsymbol{b}^{d}$ & & & 0.9980 & 0.9953 & 0.9932 & 0.9989 & 0.9983 \\
\hline $\boldsymbol{k}^{e}$ & & & 1 & & 1 & & \\
\hline
\end{tabular}

${ }^{a}$ Experimental data taken from ref. $8 \mathrm{~b} ; \boldsymbol{a}$ and $\boldsymbol{b}$ - the probabilities of stereoselective insertion on the open and crowded metallocene faces, respectively; $\boldsymbol{k}-$ the probability of

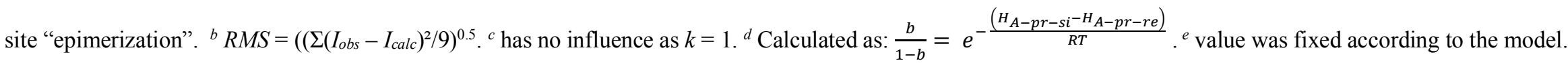


$C_{2}$-Symmetric System (3). Similar energetic data for the four possible structures for propylene insertion at the first, second and third steps of polymerization were determined for the cationic system $\left[\mathrm{rac}-\left\{\mathrm{Me}_{2} \mathrm{Si}(2-\mathrm{Me}-4-\mathrm{Ph}-\mathrm{Ind})_{2}\right\} \mathrm{ZrMe}\right]^{+}$(3); representative data are summarized in Table 5. By analogy with the $\{\mathrm{Cp} / \mathrm{Flu}\}$ counterparts, system 3 revealed a strong tendency to afford regioselective primary insertions and also exhibited no stereopreference at the very first insertion step. For instance, the activation barrier for the sec-si and sec-re insertions are much higher (by $5-10 \mathrm{kcal}_{\mathrm{mol}}{ }^{-1}$ ); this is because the methyl group of propylene points toward indenyl ligands in both structures, and in the sec-si structure it induces the rotation of the phenyl ring in order to avoid steric repulsion (for the second insertion step, see Fig. 3). Also, formation of the corresponding primary insertion products proved to be favored thermodynamically, apparently stabilized by agostic interactions.

Starting from the second insertion step, system $\mathbf{3}$ becomes highly stereoselective. The latter fact stems from a significant difference $\left(\Delta \Delta H^{\ddagger}=4.3-4.6 \mathrm{kcal} \cdot \mathrm{mol}^{-1}\right)$ between the barriers of the stereoselective (pr-si) insertion and misinsertion (pr-re). Indeed, in the structure of the transition state for the pr-re insertion (Fig. 3), the methyl group of propylene points towards the 4-indenyl phenyl substituent and lies in cis position with respect to the $i \operatorname{Pr}$ substituent of the iso-butyl group (representing the growing polymeryl chain), which in turn generates major steric congestion. In the corresponding structure for the stereoregular pr-si insertion, these repulsions are minimized. These results are in agreement with an operative enantiomorphic site control mechanism.

Of note, system 3 features significantly lower propylene insertion barriers into $\mathrm{Zr}$ polymeryl bond $\left(\Delta \Delta H^{\ddagger}=3-6 \mathrm{kcal} \cdot \mathrm{mol}^{-1}\right)$ than those calculated for the $\{\mathrm{Cp} / \mathrm{Flu}\}$-type systems 1-R and 2. This fact is diagnostic of a higher propensity of the former system to polymerize propylene, which is actually in line with the observed superior productivities of $\{\mathrm{SBI}\}$-based catalysts as compared to those of $\{\mathrm{Cp} / \mathrm{Flu}\}$-based systems. ${ }^{11}$ 


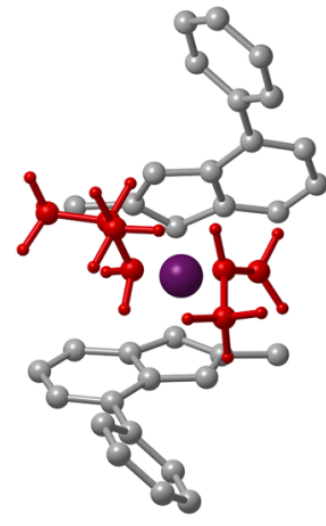

pr-si

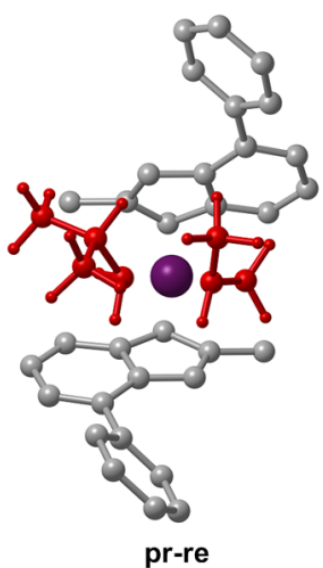

pr-re

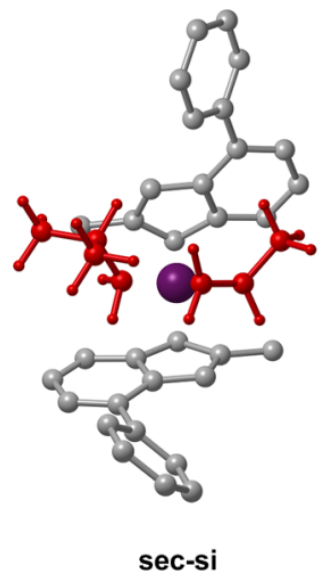

sec-si

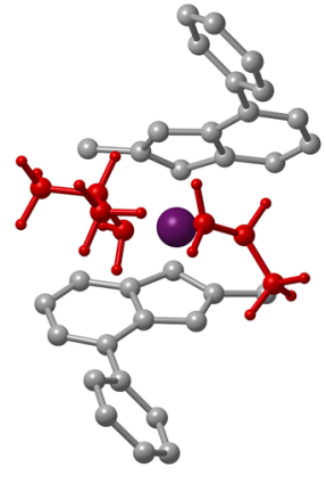

sec-re

Figure 3. Optimized transition state structures for the four possible propylene insertions in system 3 at the second insertion step. Hydrogen atoms of the indenyl moieties and those of the entire $\mathrm{SiMe}_{2}$ bridge are omitted for clarity. The propylene molecule and the iso-butyl group are depicted in red.

We also probed modeling of the microstructure of iPP produced with system 3 using a one-parameter model (Table 6). The model describes accurately enough (in terms of RMS) the experimental pentad distributions for samples obtained at high polymerization temperature $\left(80-95{ }^{\circ} \mathrm{C}\right)$. The near-one values of the probabilistic descriptor $\boldsymbol{a}$, DFT computed for the second and third insertion steps at different temperatures, are all in agreement with very high isoselectivity of the catalytic system. However, the theoretical model predicts much higher stereoselectivity than that achieved experimentally. This discrepancy again may stem from insertion side-processes, like regioirregular secondary insertion, which are not included in the theoretical statistical model.

Table 5. Energetic data calculated for the first three propylene insertion steps in system $\mathbf{3}^{a}$

\begin{tabular}{|c|c|c|c|c|}
\hline \multirow{2}{*}{ Reaction } & & $\begin{array}{c}\Delta H \\
\left(1^{\text {st }} \text { insertion }\right)\end{array}$ & $\begin{array}{c}\Delta H \\
\left(2^{\text {nd }} \text { insertion }\right)\end{array}$ & $\begin{array}{c}\Delta H \\
\left(3^{\mathrm{d}} \text { insertion }\right)\end{array}$ \\
\hline \multirow{3}{*}{ pr-si } & Adduct & -5.3 & -3.9 & -3.8 \\
& TS & 4.7 & 5.8 & 5.4 \\
& Product & $(10.0)$ & $(9.8)$ & $(9.2)$ \\
\hline pr-re & Adduct & -15.3 & -18.4 & -15.5 \\
\hline
\end{tabular}




\begin{tabular}{|c|c|c|c|c|} 
& & 5.1 & 10.6 & 9.7 \\
& TS & $(10.1)$ & $(12.3)$ & $(11.4)$ \\
& Product & -15.3 & -18.4 & -18.9 \\
\hline \multirow{3}{*}{ sec-si } & Adduct & -2.8 & 1.1 & -0.2 \\
& TS & 15.4 & 15.0 & 15.7 \\
& Product & $(18.2)$ & $(16.1)$ & $(15.9)$ \\
\hline \multirow{3}{*}{ sec-re } & Adduct & -2.4 & -10.2 & -10.7 \\
& & -4.3 & -1.9 & -1.4 \\
& TS & 9.5 & 8.9 & 8.5 \\
& Product & $(13.8)$ & $(10.8)$ & $(9.9)$ \\
\hline
\end{tabular}

${ }^{a}$ The values for the insertion barriers were calculated as $\Delta H^{f_{\text {ins }}}=H_{\mathrm{TS}}-H_{\text {Reactants. }}$ The values in brackets for the insertion barriers were calculated as $\Delta H^{\neq}=H_{\mathrm{TS}}-H_{\text {Adduct. }}$

Table 6. Pentad distributions (\%) and corresponding probability parameters determined experimentally for system $\mathbf{3}$, and those simulated using a one-parameter model and DFT computed. $^{a}$

\begin{tabular}{|c|c|c|c|c|c|c|c|c|c|c|}
\hline \multirow{4}{*}{$\frac{\mathbf{T},\left[{ }^{\circ} \mathrm{C}\right]}{M_{\mathbf{n}}\left[\times 10^{3}\right]}$} & \multirow[b]{2}{*}{ Exp } & \multirow{3}{*}{$\frac{\text { Calc }}{80)}$} & \multirow[b]{2}{*}{ Exp } & \multirow{3}{*}{$\frac{\text { Calc }}{95)}$} & \multicolumn{6}{|c|}{ Calculated from DFT data } \\
\hline & & & & & \multicolumn{3}{|c|}{$2^{\text {nd }}$ insertion } & \multicolumn{3}{|c|}{$3^{\mathrm{d}}$ insertion } \\
\hline & $60(80)$ & & $60(95)$ & & 25 & 80 & 95 & 25 & 80 & 95 \\
\hline & n.d. & - & n.d. & - & & & & & & \\
\hline 1,2 ins & 99.6 & - & 98.9 & - & & & & & & \\
\hline$[\mathrm{mmmm}]$ & 97.8 & 97.8 & 92.5 & 92.7 & 99.8 & 99.4 & 99.2 & 99.7 & 98.9 & 98.6 \\
\hline$[\mathrm{mmmr}]$ & 0.8 & 0.9 & 2.5 & 2.8 & 0.1 & 0.2 & 0.3 & 0.1 & 0.4 & 0.6 \\
\hline$[r m m r]$ & 0.0 & 0.0 & 0.7 & 0.0 & 0.0 & 0.0 & 0.0 & 0.0 & 0.0 & 0.0 \\
\hline$[m m r r]$ & 0.9 & 0.9 & 2.7 & 2.8 & 0.1 & 0.2 & 0.3 & 0.1 & 0.4 & 0.6 \\
\hline $\begin{array}{l}{[\mathrm{mrmm}]} \\
+[\mathrm{rmrr}]\end{array}$ & 0.2 & 0.0 & 0.6 & 0.1 & 0.0 & 0.0 & 0.0 & 0.0 & 0.0 & 0.0 \\
\hline$[m r m r]$ & 0.0 & 0.0 & 0.0 & 0.0 & 0.0 & 0.0 & 0.0 & 0.0 & 0.0 & 0.0 \\
\hline [rrrr] & 0.0 & 0.0 & 0.0 & 0.0 & 0.0 & 0.0 & 0.0 & 0.0 & 0.0 & 0.0 \\
\hline [mrrr $]$ & 0.0 & 0.0 & 0.0 & 0.0 & 0.0 & 0.0 & 0.0 & 0.0 & 0.0 & 0.0 \\
\hline$[m r r m]$ & 0.3 & 0.4 & 1.1 & 1.4 & 0.0 & 0.1 & 0.2 & 0.1 & 0.2 & 0.3 \\
\hline total & 99.9 & 100.0 & 100.0 & 100.0 & 100.0 & 100.0 & 100.0 & 100.0 & 100.0 & 100.0 \\
\hline RMS & - & 0.08 & - & 0.33 & - & 0.61 & 2.52 & - & 0.42 & $2.2^{n}$ \\
\hline$a^{c}$ & - & 0.9956 & - & 0.9850 & 0.9996 & 0.9988 & 0.9984 & 0.9993 & 0.9978 & 0.9972 \\
\hline
\end{tabular}

${ }^{a}$ Experimental data taken from ref. $11 ; \boldsymbol{a}$ - the probability of stereoselective insertion. ${ }^{b} R M S=\left(\left(\Sigma\left(I_{o b s}-\right.\right.\right.$ $\left.\left.I_{\text {calc }}\right)^{2} / 9\right)^{0.5} \cdot{ }^{c}$ Calculated as: $\frac{a}{1-a}=e^{-\frac{\left(H_{p r-s i}-H p r-r e\right)}{R T}}$. 
The validity of chain "stationary" insertion mechanism (i.e., site epimerization by backskip) for isoselective $C_{1}$-symmetry $\{\mathrm{Cp} / \mathrm{Flu}\}$-type metallocenes was demonstrated using a recently developed theoretical model ${ }^{21}$ for the investigation of stereocontrol mechanism of propylene polymerization. However, an alternative, yet less stereoselective alternating mechanism of stereocontrol can be operational at the same time. In line with previously reported experimental results, ${ }^{8 b}$ steric bulkiness imposed by the 3-cyclopentadienyl substituent (i.e., 2-methyl-2-adamantyl $v s t \mathrm{Bu}$ ) is shown to be beneficial for the suppression of this alternative mechanism. Eventually, this makes the more stereoselective site epimerization mechanism to be unique for the heavily 3-cyclopentadienyl-substituted $\{\mathrm{Cp} / \mathrm{Flu}\}$-type metallocenes. On the other hand, introduction of a bulkier group ( $\mathrm{Ph} v s \mathrm{Me})$ into the 5-cyclopentadienyl position facilitates the alternating mechanism, eventually affording a less stereoselective catalyst. For the $C_{2}$-symmetric $\{\mathrm{SBI}\}$-type system $3,{ }^{4}$ the well-accepted chain migratory stereocontrol mechanism was corroborated using the new theoretical model..$^{21}$

Implementation of the computed thermochemical data into the probabilistic analysis allowed reproducing and predicting statistical pentad distributions for iPPs obtained with both families of metallocene catalysts operating via dissimilar stereocontrol mechanisms. Further studies on the application of this theoretical model for modeling/understanding of other metallocene systems, as well as computer-aided design of new more performing/stereoselective polymerization catalytic systems, are underway in our laboratories.

\section{ACKNOWLEDGMENTS}

This work was supported by TOTAL SA and TOTAL Research \& Technology Feluy. L. Maron and L. Castro are grateful to the CALMIP for computation time. 


\section{REFERENCES and NOTES}

(a) Resconi, L.; Fritze, C. Polypropylene Handbook; Pasquini, N. Ed.; Hanser Publishers, Munich, 2005, pp 107-147. (b) Kaminsky, W. Macromolecules 2012, 45, 3289-3297. (c) Fink, G.; Brintzinger, H. H. Metal-Catalysis in Industrial Organic Processes; Chiusoli, G. P.; Maitlis, P. M., Eds.; Royal Society of Chemistry, Colchester, 2006, pp 218-254. (d) Razavi, A. C. R. Acad. Sci., Chem. 2000, 3, 615-625.

(a) Resconi, L.; Cavallo, L.; Fait, A.; Piemontesi, F. Chem. Rev. 2000, 100, 1253-1345.

(b) Busico, V.; Cipullo, R. Prog. Polym. Sci. 2001, 26, 443-533.

(a) Guerra, G.; Cavallo, L.; Moscardi, G.; Vacatello, M.; Corradini, P. Macromolecules 1996, 29, 4834-4845. (b) Guerra, G.; Longo, P.; Cavallo, L.; Corradini, P.; Resconi, L. J. Am. Chem. Soc. 1997, 119, 4394-4403. (c) Toto, M.; Cavallo, L.; Corradini, P.; Moscardi, G.; Resconi, L.; Guerra, G. Macromolecules 1998, 31, 3431-3438. (d) Moscardi, G.; Resconi, L. Organometallics 2001, 20, 1918-1931. (e) Borelli, M.; Busico, V.; Cipullo, R.; Ronca, S.; Budzelaar, P. H. M. Macromolecules 2003, 36, 8171-8177. (f) Guerra, G.; Corradini, P.; Cavallo, L. Macromolecules 2005, 38, 39733976. (g) Correa, A.; Talarico, G.; Cavallo, L. J. Organomet. Chem. 2007, 692, 4519-

4527. (h) Wondimagen, T.; Wang, D.; Razavi, A.; Ziegler, T. Organometallics 2008, 27, 6434-6439. (i) Talarico, G.; Budzelaar, P. H. M. Organometallics 2014, 33, 59745982.

Laine, A.; Coussens, B. B.; Hirvi, J. T.; Berthoud, A.; Friederichs, N.; Severn, J. R.; Linnolahti, M. Organometallics 2015, 34, 2415-2421. (c) Kuklin, M. S.; Virkkunen, V.; Castro, P. M.; Resconi, L.; Linnolahti, M. Eur. J. Inorg. Chem. 2015, 4420-4428. 
(a) Van der Leek, Y.; Angermund, K.; Reffke, M.; Kleinschmidt, R.; Goretzki, R.; Fink, G. Chem. Eur. J. 1997, 3, 585-591. (b) Chen, M.-C.; Roberts, J. A. S.; Marks, T. J. J. Am. Chem. Soc. 2004, 126, 4605-4625. (c) Tomasi, S.; Razavi, A.; Ziegler, T. Organometallics 2007, 26, 2024-2036.

(a) Razavi, A.; Thewalt, U. Coord. Chem. Rev. 2006, 250, 155-169. (b) Razavi, A.; Belia, V.; Baekelmans, D.; Slawinsky, M.; Sirol, S.; Peters, L.; Thewalt, U. Kinetics and Catalysis 2006, 47, 257-267. (c) Boggioni, L.; Cornelio, M.; Losio, S.; Razavi, A.; Tritto, I. Polymers 2017, 9, 581-598.

7 Roberts, J. S. A.; Chen, M.-C.; Seyam, A. M.; Li, L.; Zuccaccia, C.; Stahl, N. G.; Marks, T. J. J. Am. Chem. Soc. 2007, 129, 12713-12733.

(a) Miller, S. A.; Bercaw, J. Organometallics 2002, 21, 934-945. (b) Miller, S. A.; Bercaw, J. Organometallics 2006, 25, 3576-3592.

(a) Wang, D.; Tomasi, S.; Razavi, A.; Ziegler, T. Organometallics 2008, 27, 28612867. (b) Wondimagegn, T.; Wang, D.; Razavi, A.; Ziegler, T. Organometallics 2009, 28, 1383-1390. (c) Tomasi, S.; Razavi, A.; Ziegler, T. Organometallics 2009, 28, 2609-2618.

Angermund, K.; Fink, G.; Jensen, V. R.; Kleinschmidt, R. Macromol. Rapid Commun. 2000, 21, 91-97.

(a) Kirillov, E.; Marquet, N.; Bader, M.; Razavi, A.; Belia, V.; Hampel, F.; Roisnel, T.; Gladysz, J. A.; Carpentier, J.-F. Organometallics 2011, 30, 263-272. (b) Bader, M.; Marquet, N.; Kirillov, E.; Roisnel, T.; Razavi, A.; Lhost, O.; Carpentier, J.-F. Organometallics 2012, 31, 8375-8387. 
Farina, M.; Di Silvestro, G.; Terragni, A. Macromol. Chem. Phys. 1995, 196, 353-367.

(e) Di Silvestro, G.; Sozzani, P.; Terragni, A. Macromol. Chem. Phys. 1996, 197, 32093228.

(a) Yu, Z.; Chien, J. C. W. J. Polym. Sci. A: Polym. Chem. 1995, 33, 125-135. (b) Yu, Z.; Chien, J. C. W. J. Polym. Sci. A: Polym. Chem. 1995, 33, 1085-1094.

Angermund, K.; Fink, G.; Hensen, V. R.; Kleinschmidt, R. Chem. Rev. 2000, 100, $1457-1470$.

Bochmann, M. Organometallics 2010, 29, 4711-4740.

For a recent report on the reactivity of dichloro metallocenes 1-Me and $\mathbf{3}$ with MAO and molecular activators, see: Theurkauff, G.; Bader, M.; Marquet, N.; Bondon, A.; Roisnel, T.; Guegan, J.-P.; Amar, A.; Boucekkine, A.; Carpentier, J.-F.; Kirillov, E. Organometallics 2016, 35, 258-276.

(a) Chan, M. S. W.; Vanka, K.; Pye, C. C.; Ziegler, T. Organometallics 1999, 18, 46244636. (b) Klesing, A. Phys. Chem. Chem. Phys. 1999, 1, 2373-2377. (c) Vanka, K.; Chan, M. S. W.; Pye, C. C.; Ziegler, T. Organometallics 2000, 19, 1841-1849. (d) Lanza, G.; Fragala, I. L.; Marks, T. J. J. Am. Chem. Soc. 2000, 122, 12764-12777. (e) Lanza, G.; Fragala, I. L.; Marks, T. J. Organometallics 2002, 21, 5594-5612.

(a) Zurek, E.; Ziegler, T. Prog. Polym. Sci. 2004, 29, 107-148. (b) Ghiotto, F.; Pateraki, C.; Tanskanen, J.; Severn, J. R.; Luehmann, N.; Kusmin, A.; Stellbrink, J.; Linnolahti, M.; Bochmann, M. Organometallics 2013, 32, 3354-3362.

Shiomura, T.; Asanuma, T.; Inoue, N. Macromol. Rapid Commun. 1996, 17, 9-14. 
22 It should be noted that these agostic interactions may be absent when a counterion (not considered by this theoretical model) is present and coordinated to the cationic metal center.

23 Noteworthy, starting from the second insertion step, monomer coordination onto the metal center of $\{\mathrm{Cp} / \mathrm{Flu}\}$ systems became endothermic.

24 The corresponding transition state of the epimerization process can hardly be located because of a very low and smooth energetic profile.

25 As proposed in the previous theoretical study, ${ }^{9 a}$ other possible factors, like entropic factors, back-side insertion and chain epimerization may also be responsible for the lower precision of statistical modeling of pentad distributions in polymers obtained at higher temperatures. 